\title{
A More Accurate Measure of Local Public Goods: Overlapping Government Combinations as Units of Analysis
}

\author{
Samuel B. Stone \\ California State University, Fullerton, USA \\ Correspondence should be addressed to Samuel B. Stone; sstone@fullerton.edu \\ Received 21 September 2013; Accepted 10 December 2013; Published 10 February 2014
}

Academic Editor: Edoardo Marcucci

Copyright (C) 2014 Samuel B. Stone. This is an open access article distributed under the Creative Commons Attribution License, which permits unrestricted use, distribution, and reproduction in any medium, provided the original work is properly cited.

\begin{abstract}
This study posits and tests the viability of a new unit of analysis for local public goods in metropolitan areas: overlapping government combinations (OGCs). Counties, municipalities, school districts, and other special districts operate simultaneously within the same space, each providing their own set of local public goods. Residents of the same city can live within the boundaries of different counties, school districts and other special districts and thus receive (and pay for) very different quantities and qualities of public goods. Though there is a great deal of literature devoted to the variation of local public goods in a fragmented metropolitan region, there is none that cumulates the different local government types into units that represent the true bundles of local public goods that are provided to citizens and property owners. This study tackles this problem through the application of geographic information systems (GIS) to stack counties, municipalities, and school districts in the Dallas-Fort Worth-Arlington CMSA into unique OGCs. The unique OGCs are compared to their underlying component governments with respect to property tax rates and school performance and are found to be statistically distinct.
\end{abstract}

\section{Introduction}

As of this writing, there are 89,000 local governments in the United States including all counties, municipalities, school districts, and other special districts with their own governing bodies [1]. Each of these jurisdictions provides its residents and property owners with a unique set of local public goods. Most citizens and real property are located within several of these jurisdictions at once. Citizens and property owners, therefore, receive different bundles of local public goods depending on the combination of jurisdictions that overlap their homes and businesses. While it has always been possible to begin research into these bundles of local public goods from the point of view of a particular property or parcel, or from the vantage point of a single jurisdictional type, this study proposes a different track altogether. Because most Americans who live in a metropolitan area live within the boundaries of several different local governments, it makes sense to think of a metropolitan area as collection of these overlapping jurisdictional combinations. This is a novel approach because the empirical literature has not really stepped beyond parcel level studies or government-togovernment studies. There are many examples of research that do take into account and study the effect of multiple overlapping jurisdictions but there are no studies that investigate the viability of using these combinations of overlapping governments as units of analysis themselves.

This study will explore some of the literature on local government fragmentation and related fields. I make the argument that much of this research could benefit from an overlapping jurisdictional framework. This is followed by a discussion of the methods, models, and data used in this study which uses the Dallas-Fort Worth-Arlington CMSA as a test case for the overlapping government approach. The primary objective of this study is to demonstrate that, as units of analysis, overlapping government combinations are statistically distinct from their component governments, both across a metropolitan region and even within the borders of a single government. The results presented in the following section bear this out. This is followed by a discussion of those results and then a conclusion.

\section{Literature}

Since the publication of Tiebout [2] hypothesis of the efficiency of a multiplicity of local governments, an entire 
interdisciplinary subfield has emerged debating the relative merits of fragmented versus regionalized (or consolidated) local governments. The purpose of this study is not to recount the dense multidecade debate in the literature surrounding this issue, but to point out that that great body of literature was constrained to an extent by computing technology. This is not to say that the empirical literature ignored the spatial dimensions of fragmentation or used entirely nonspatial datasets. On the contrary, empirical investigation into the effects of local government fragmentation included spatial data almost from the beginning [3]. The property tax literature also has abundant examples of research that incorporate spatial data of one kind or another and multiple levels of government [4-6]. More recently, Billings and Thibodeau [7] explain the difference between nesting and overlapping units of local government and the effect this has on property values. This is crucial because numerous previous studies including a frequently cited one by Turnbull and Djoundourian [8] do not make the distinction between nested and overlapping and employ the term "overlapping" when really studying the former. Berry [9] uses a government density measure (essentially jurisdictions per county) to calculate the effect of government overlap on the size of public sector spending.

The advent of GIS software, however, enables researchers to assemble data in new ways. The assemblage that I am proposing here is a unit of analysis that more accurately reflects the totality of local public goods as it varies across a metropolitan area and as it might appear from the points of view of citizens and property owners. There are few extant spatial studies that examine the overlap of local governments. The most notable of these is by Martell [10], in which the author analyzes "unique taxing areas" (UTAs) that account for the cumulative property tax rates created by different combinations of local governments across the Denver metropolitan region. I use essentially the same method of aggregation in this study. Whereas the Martell study was concerned with just property taxes, the aim of this research is to demonstrate the suitability of these jurisdictional combinations in order to generalize to other local public goods. The term employed here, therefore, is overlapping government combination (OGC). The Minnesota Department of Revenue, incidentally, uses the same terminology as Martell in its manual for property tax administrators when describing the phenomenon [11]. This is not to be confused with similar work by Frey [12] who proposes functional, overlapping, competing jurisdictions (FOCJs) as a device to help European federal systems to achieve better fiscal equivalence. The present study is merely descriptive and takes for granted the existence of a multitude of functional and overlapping jurisdictions as is the case in most metro areas in the United States. Another study that analyzes the effect of uneven overlap of jurisdictions is Ross et al. [13]. The authors use the Herfindahl-Hirschman Index (HHI) of school district area split between municipalities as a measure of noncongruence or fragmentation. This was done across the entire state of Ohio. They find no evidence that noncongruent borders between school districts and municipalities have any effect on the resources available to those school districts or their class sizes. The relevance of this to the present study is that here fragmentation is assumed as a given in a metropolitan area.

\section{Methods, Models, and Data}

The study area includes ten of the twelve counties that make up the Core Based Statistical Area (CBSA) of Dallas-Fort Worth-Arlington. The Census population estimate for the entire CBSA for 2012 is $6,700,991$ [14]. The ten counties in this study [15-24] have combined 2012 estimated population of 6,553,270 which represents 98 percent of the CBSA population. The other two counties are Hunt and Delta and are excluded due to incomplete data. These ten counties encompass 168 municipalities and 115 independent school districts. Other special districts are excluded from this study due to incomplete spatial data. (There are 101 special districts in the study area with the power to levy property taxes that are excluded from this study. Not only was spatial data incomplete for these districts, but it was also not clear if all of these districts were active or actually levying property taxes). This may at first seem like an important omission; however, the purpose of this study is simply to examine the differences between single type jurisdictions and the layering of multiple types.

The chief public good variable employed in this study, the ad valorem legal property tax rate, is actually a proxy variable for local public goods. It is used here because it is a relatively straightforward number that is easily added from multiple jurisdictions to create a cumulative value. Data from Texas are used because there are few limits on property taxation in the state, and those that exist do not cap total liability or assessments. This enables local governments in Texas to set their own property tax rates and means that they are truly additive which lends them easily to this study. It should be reiterated that the legal property tax rate is used here for its methodological expediency rather than for how thoroughly it comprehends the concept of local public goods. (Texas allows counties, municipalities and special districts to levy a local option sales tax up to a total $2 \%$, for instance. This provides a substantial source of revenue for many local governments in the state.)

An additional local public good variable included here is school district quality. As in most other states, Texas school districts have locally elected boards and are administered locally. Funding for school districts is derived mostly from property taxes with minimal state aid, though the state does redistribute school district property tax revenue throughout the state. The Texas Education Agency (TEA) [25] sets a wide variety of guidelines that govern how districts operate and also provides test score results at both the school and district level. District level results for standardized tests covering math, reading, and writing are used here as per the literature on this topic [26].

The spatial data for county, municipality, and school district boundaries come from the US Census Bureau. The tax rate data come from the Central Appraisal Districts (CAD) associated with each county. CADs are responsible for appraisal and assessment of all property and maintain 
TABLE 1: Descriptive statistics for property tax rates of counties, municipalities and school districts.

\begin{tabular}{lccc}
\hline & Country & City & School district \\
\hline Mean & 0.3250 & 0.5493 & 1.4122 \\
Standard error & 0.0256 & 0.0155 & 0.0133 \\
Median & 0.3093 & 0.5865 & 1.4188 \\
Standard deviation & 0.0809 & 0.2014 & 0.1426 \\
Kurtosis & 1.3578 & -0.2199 & -0.6214 \\
Skewness & 1.1593 & -0.1481 & -0.1650 \\
Range & 0.2620 & 1.0552 & 0.5500 \\
Minimum & 0.2400 & 0.0503 & 1.1200 \\
Maximum & 0.5020 & 1.1054 & 1.6700 \\
$N$ & 10 & 168 & 115 \\
\hline
\end{tabular}

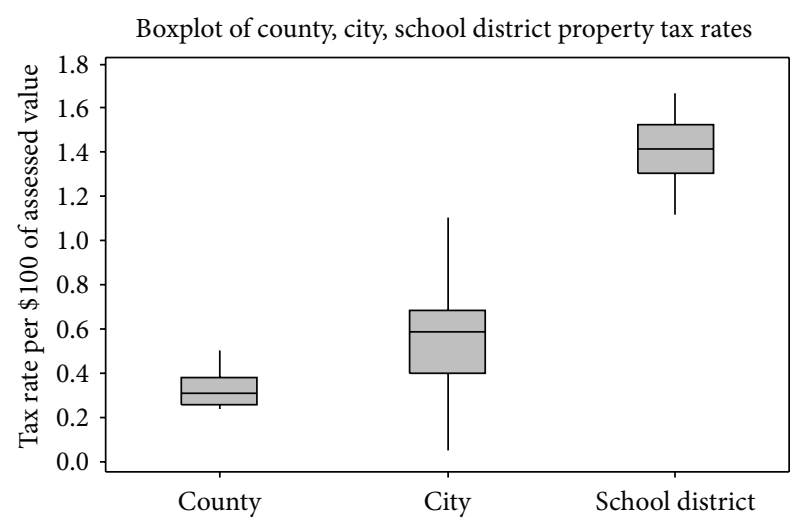

FIGURE 1: Boxplot of property tax rates for counties, municipalities and school districts.

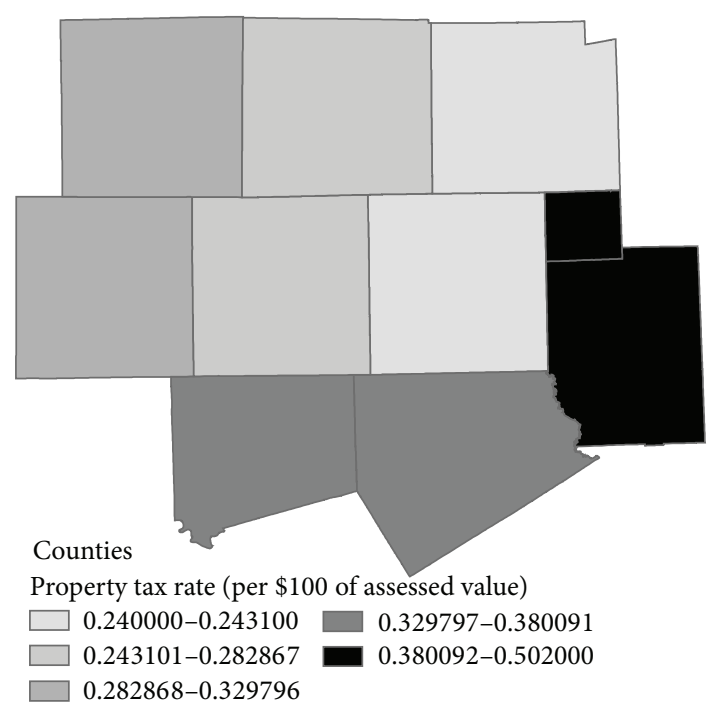

Figure 2: County property tax rates within study area.

schedules of tax rates for all jurisdictions levying property taxes within their borders (which are coterminous with county boundaries). Tax rates are reported per $\$ 100$ of assessed value. Rates are uniform with respect to property type, though homestead exemptions are almost universal and vary considerably with respect to size and structure.

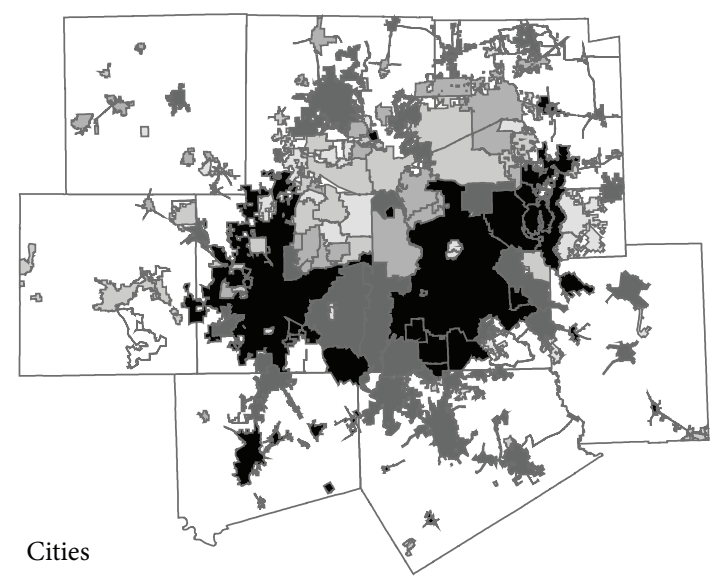

Property tax rate (per $\$ 100$ of assessed value)

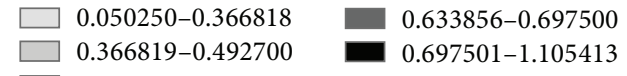

$0.492701-0.633855$

FIgURE 3: City property tax rates within study area.

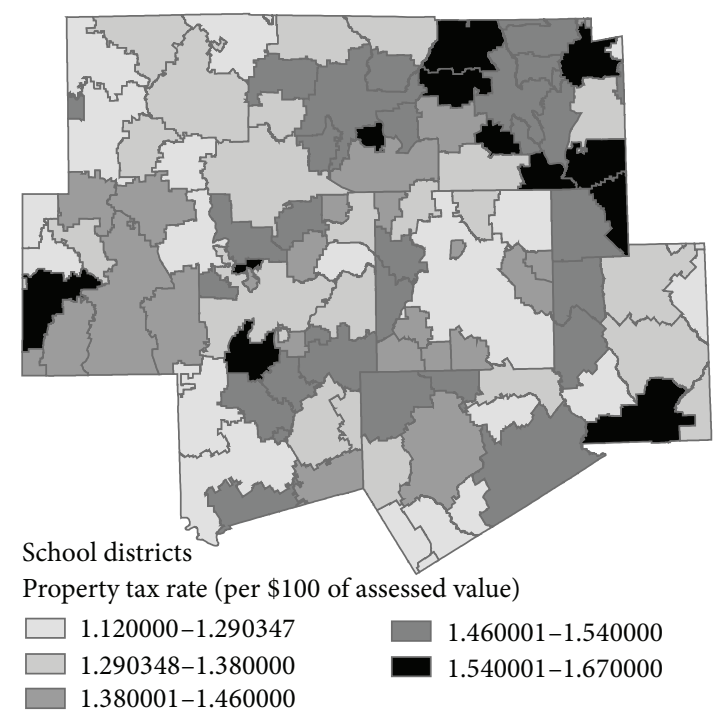

FIGURE 4: School district property tax rates within study area.

Table 1 presents descriptive statistics for tax rates among the three jurisdictional types included in this study.

Tests for normality reveal that the variables are not normally distributed. Figure 1 is a boxplot that depicts the ranges in property tax rates between the three government types.

The process for creating OGCs from these data is conceptually straightforward. The schedules of tax rates for all of the counties are consolidated into schedules for all counties, cities, and schools. These schedules are then appended to the attribute tables of the shapefiles for each of the jurisdictional types. These are displayed graphically in Figures 2, 3, and 4, where, for illustrative purposes, property tax rates are divided by quintile.

The shapefiles for the three sets of governments are then combined using a spatial union creating the unique OGCs. 


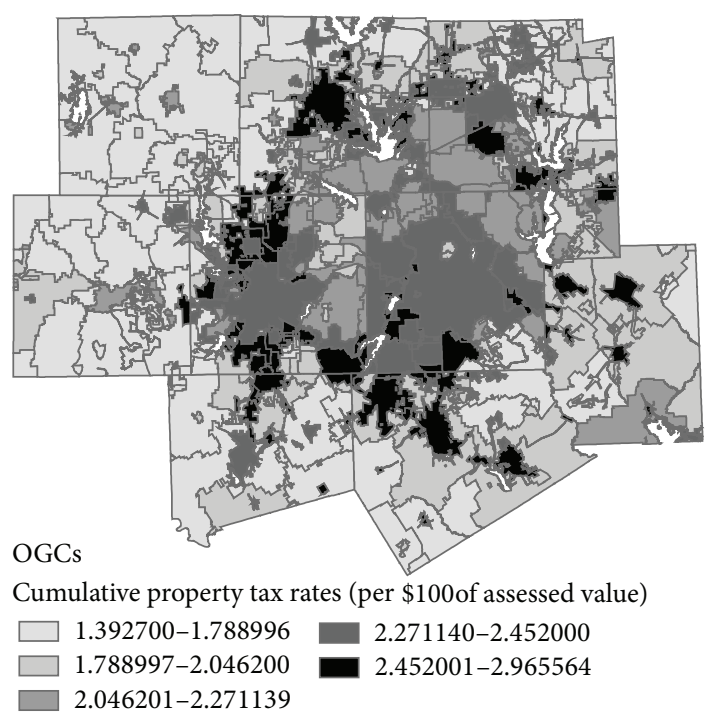

FiguRE 5: OGC property tax rates.

The attribute table for this new shapefile still contains separate fields (columns) for the property tax rates of the constituent governments. These fields are then summed resulting in the cumulative tax rates. Since a number of governments actually overlap each other in more than one location, duplicates are removed. There are also a number of lakes within the study area. Some of the OGCs fall inside these lakes, so they are removed from the dataset as well. The final product is displayed in Figure 5 below.

Descriptive statistics for the OGCs are presented in Table 2. Perhaps the most important characteristic of the OGC cumulative property tax rates is that they display a nonnormal distribution.

The objective of the analysis is to demonstrate that OCGs constitute a unit of analysis separate and distinct from individual governments. As such, the statistical tools employed in this study are rather simple and include Levene's test for homogeneity of variances. Tests for spatial autocorrelation are also performed and include the Global Moran's I and Local Indicators of Spatial Autocorrelation (LISA) (Figures $6,7,8$, and 9). Finally, a rudimentary measure of government performance (school district test performance/cumulative property tax rate) is constructed to allow for a comparison of school districts versus OGCs.

\section{Results and Discussion}

Due to the nonnormal distributions, a Levene's test is used to test for homogeneity of variances across governmental types. Results are reported in Table 3 and include the Brown and Forsythe calculation using the median which is especially robust to nonnormality.

The tests for homogeneity of variances are all statistically significant which demonstrates that the distributions are distinct and independent.

The following statistics are measures of spatial autocorrelation. Spatial autocorrelation is a measure of the degree to

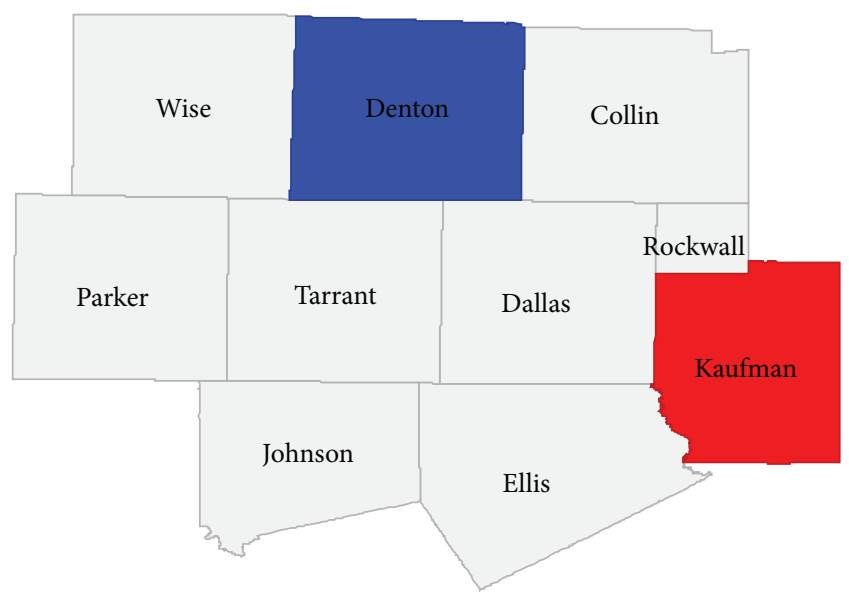

FIGURE 6: LISA for counties.

TABLE 2: Descriptive statistics for unique OGC cumulative property tax rates.

\begin{tabular}{lc}
\hline & Cumulative property tax rate \\
\hline Mean & 2.1750 \\
Median & 2.2263 \\
Mode & 2.3090 \\
Standard deviation & 0.3252 \\
Kurtosis & -0.5946 \\
Skewness & -0.3664 \\
Range & 1.5729 \\
Minimum & 1.3927 \\
Maximum & 2.9656 \\
Count & 532 \\
\hline
\end{tabular}

TABLE 3: Tests for homogeneity of variance between OGCs and other governmental types.

\begin{tabular}{lcccc}
\hline OGCs versus & $\begin{array}{c}\text { Levene's } F \\
\text { based on } \\
\text { mean }\end{array}$ & $\operatorname{Pr}>F$ & $\begin{array}{c}\text { Brown Forsythe } \\
F \text { based on } \\
\text { median }\end{array}$ & $\operatorname{Pr}>F$ \\
\hline City & 45.52 & 0.000 & 39.85 & 0.000 \\
School district & 74.18 & 0.000 & 63.69 & 0.000 \\
County & 12.49 & 0.000 & 10.77 & 0.001 \\
All types & 41.41 & 0.000 & 35.72 & 0.000 \\
\hline
\end{tabular}

which the values associated with individual cases are related to each other with respect to the cases proximity to each other. The first statistic is Moran's I for global spatial autocorrelation. Moran's $I$ is measured on a scale from -1 to 1 . A value of -1 indicated perfect dispersion, a value of 1 indicated perfect autocorrelation, and a value of 0 indicates perfect randomness. Two separate methods are used for weighting: first order queen contiguity and arc distance from centroids (Contiguity measures are described in terms of chess pieces. Queen contiguity means that cases are considered to be contiguous if their boundaries touch in any way, even if it is only at a corner. First order contiguity means that contiguity only counts between the two cases that are touching rather than including a third case that is touching the second one. 
TABLE 4: Global spatial autocorrelation of property tax rates for all governmental types and OGCs.

\begin{tabular}{|c|c|c|}
\hline & \multicolumn{2}{|c|}{ Global Moran's I } \\
\hline & $\begin{array}{l}\text { 1st order queen } \\
\text { contiguity }\end{array}$ & $\begin{array}{l}\text { Arc distance from } \\
\text { centroids }\end{array}$ \\
\hline Cities & 0.1495 & -0.0049 \\
\hline Counties & 0.1344 & 0.1713 \\
\hline School districts & 0.2642 & 0.1515 \\
\hline OGCs & 0.3473 & 0.0005 \\
\hline
\end{tabular}

Arc distance from centroids measures the proximity of cases as the distance between their center points. It does this taking into account the curvature of the Earth (arc distance), while the center point (centroid) is calculated as a weighted distance from every point along the case's boundary.) Results are presented in Table 4.

The results show that amongst cities, there is near randomness of tax rates and the values are on the dispersion side. Counties have a very low level of spatial autocorrelation among them, as do school districts. The results for the OGCs, however, are very different depending on the weighting used. For the contiguity measure, there is moderate positive spatial autocorrelation. For the distance measure, there is almost perfect randomness. These findings suggest that OGCs possess different spatial properties than their component governments.

Another spatial statistic that can help elucidate patterns is a measure of Local Indicators of Spatial Autocorrelation (LISA) prescribed by Anselin [27]. Below are maps of the governments by type. Dark red indicates that for that case the value (tax rate) is high and it is spatially autocorrelated to its contiguous neighbors with high tax rates. Dark blue indicates that the value is low and it is spatially autocorrelated to its contiguous neighbors with low tax rates.

The LISA cluster maps indicate that there are very different patterns of local spatial autocorrelation for each of the government types and for the OGCs. Not only do the OGCs have the greatest amount of local spatial autocorrelation, but the overall pattern most closely resembles what one would expect of fragmented metropolitan areas: higher tax rates in the urban core (two cores in this case) and low tax rates on the urban fringe.

Finally, school district rating and property tax rate are combined to create a rough measure of government performance per tax rate. Meier and O'Toole [26] use passage rates for reading, writing, and math on the state standardized tests as a measure of school performance. Passage rates on the same tests are used here at the school district level and the three passage rates are averaged. Then I create a ratio of performance to the OGC cumulative property tax rates. Histograms and descriptive statistics for this ratio across both school district and OGCs are presented in Figures 10 and 11 below.

Once again, OGCs and a single government type (in this case, school districts) have very different distributions, underscoring the distinctiveness of OGCs as a unit of analysis. A boxplot is presented in Figure 10 below displaying the

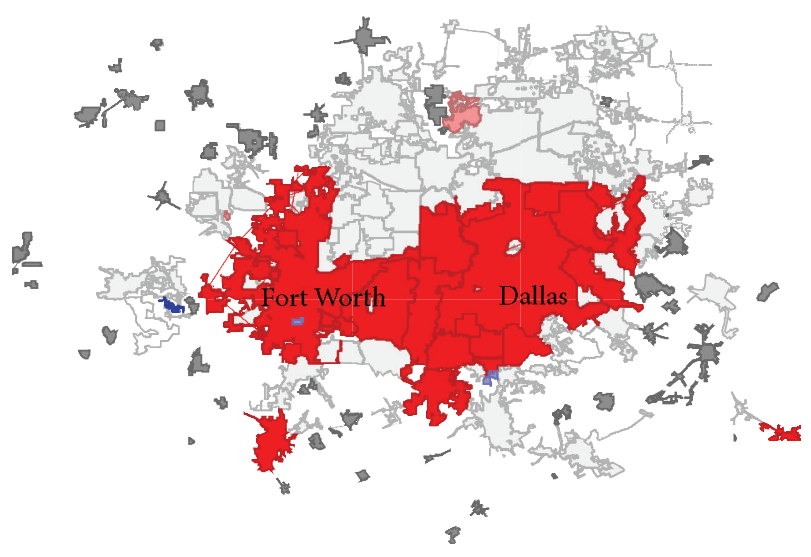

FIGURE 7: LISA for cities.

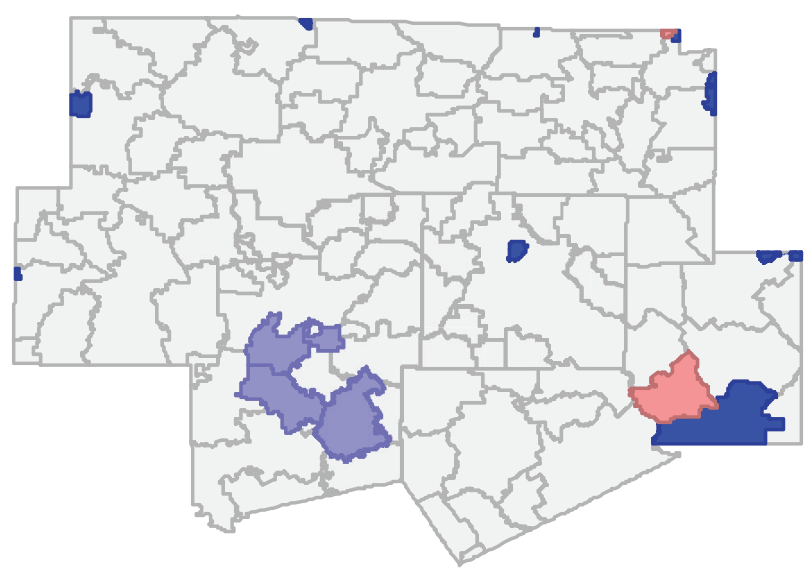

FIgURe 8: LISA for school districts.

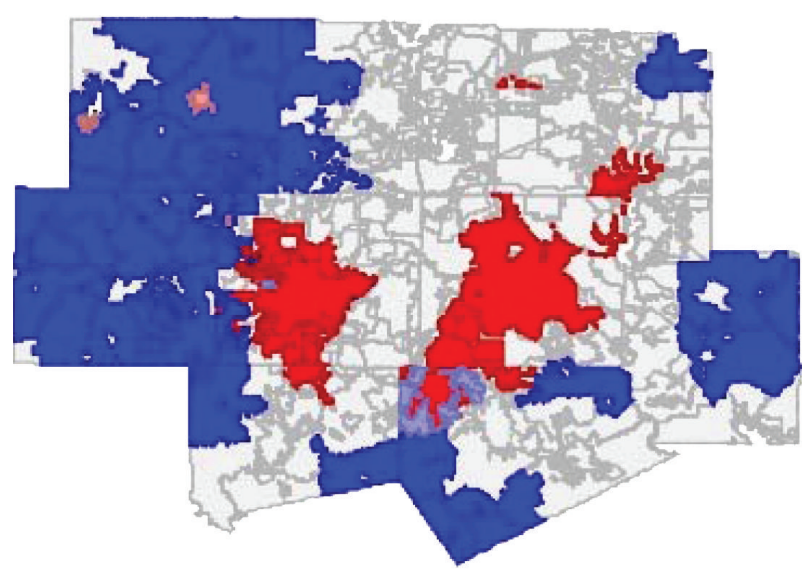

Figure 9: LISA for OGCs.

variation of the ratio across the cities in the study area with populations greater than 100,000 . This figure simply meant to give the reader a sense of the variation of OGC tax rates within the largest cities. The city with the greatest range, Fort Worth, has a range of 13.18 which represents 33 percent of the total range for all OGCs in the study area. Richardson, with a range of almost 6 percent of the study area range, has 

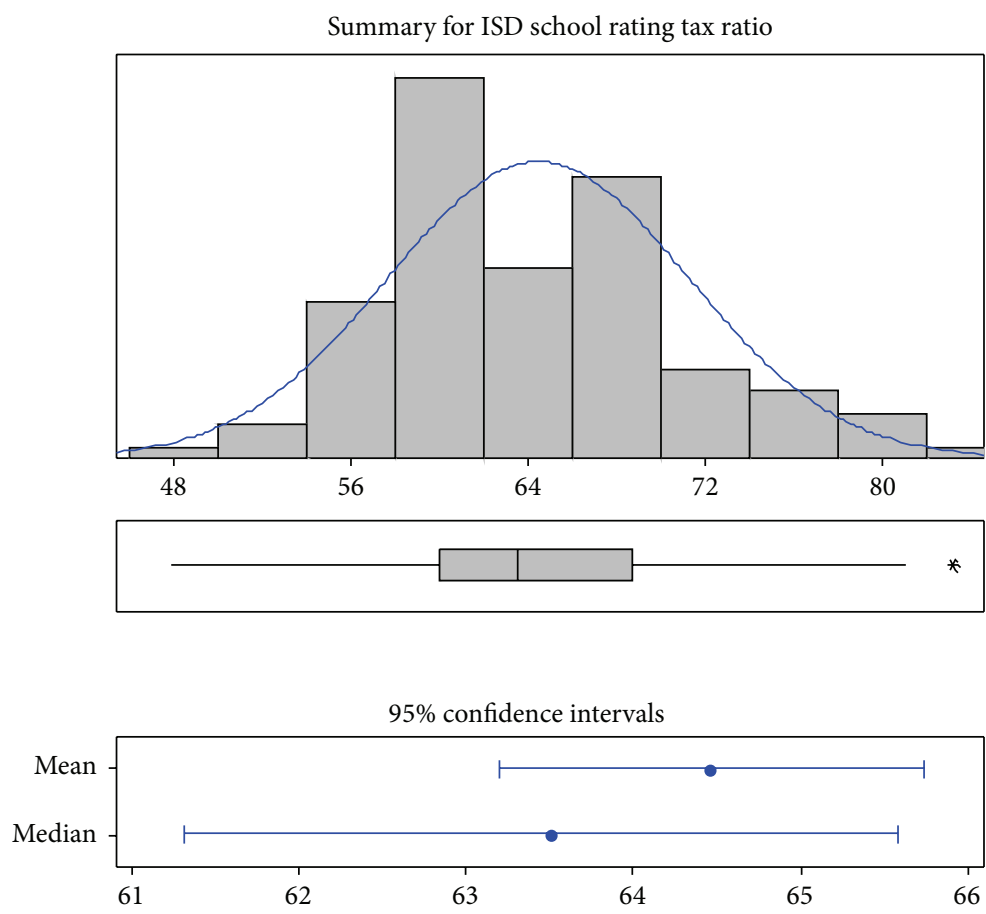

\begin{tabular}{|cc|}
\hline Anderson-darling normality test \\
A-squared & 0.97 \\
$P$ value $<$ & 0.014 \\
\hline Mean & 64.461 \\
StDev & 6.807 \\
Variance & 46.337 \\
Skewness & 0.449070 \\
Kurtosis & 0.130843 \\
$N$ & 113 \\
\hline Minimum & 47.904 \\
1st quartile & 59.991 \\
Median & 63.507 \\
3rd quartile & 68.659 \\
Maximum & 83.172 \\
\hline $95 \%$ confidence interval for mean \\
63.192 & 65.730 \\
$95 \%$ confidence interval for median \\
61.314 & 65.580 \\
$95 \%$ confidence interval for StDev \\
6.020 & 7.832 \\
\hline
\end{tabular}

FIGURE 10: Histogram and descriptive statistics for ISD school rating tax ratio.
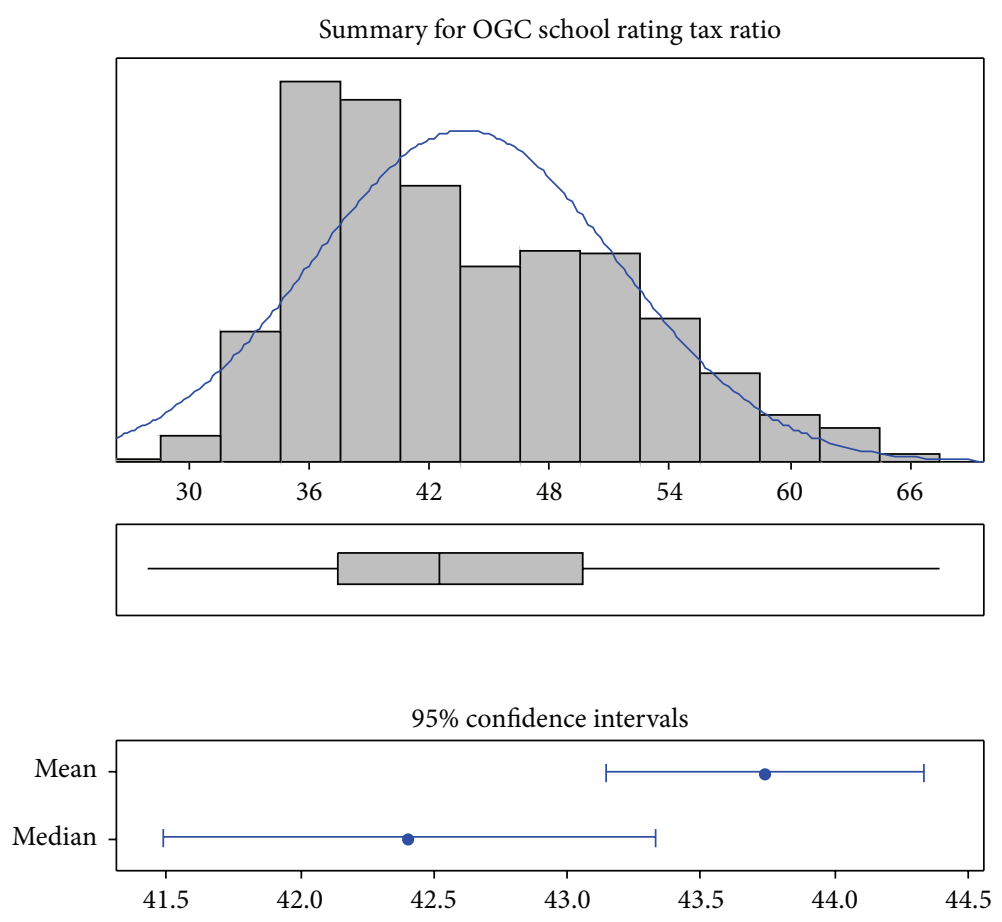

FIGURE 11: Histogram and descriptive statistics for OGC school rating tax ratio.

the smallest range of the 12 cities displayed here. The average range for these cities is 5.57, which represents about 14 percent of the total study area range for this variable.

The purpose of the analyses performed was to examine to what extent are OGCs distinct from their component governments in order that they might be treated as separate units of analysis. Using property tax rate as a variable, tests for homogeneity of variances provide statistically significant evidence that the distribution of cumulative property tax rates for OGCs is distinct from the distributions of property tax 


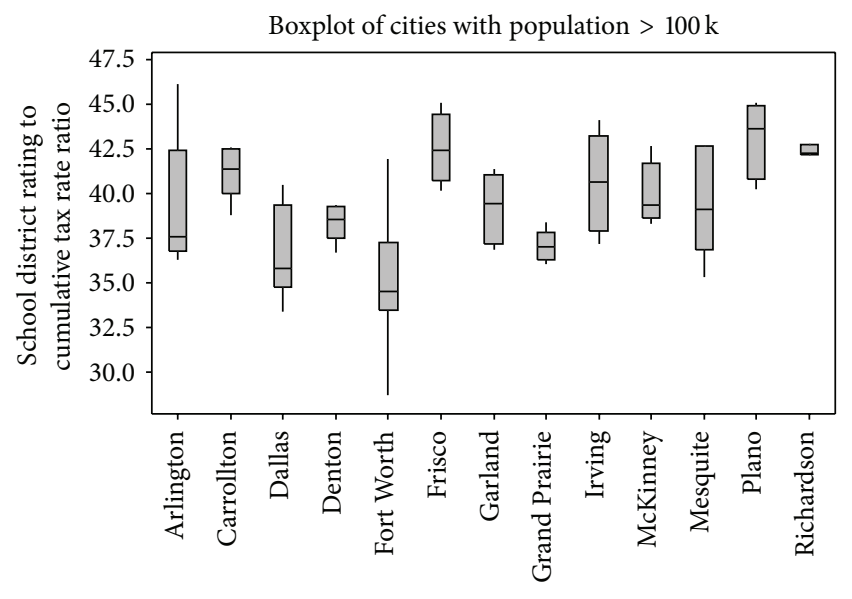

FIGURE 12: Within city variation of school district performance to OGC cumulative property tax rate.

rates for the other governmental types. This strongly supports the hypothesis that OGCs may be considered different units of analysis. In particular, this supports the notion that the noncoterminous overlapping of different governmental types produces unique aggregations of local public goods.

Tests for global spatial autocorrelation produce different results depending on the method used. The fact that the results may be artifacts of the methodology is not an encouraging sign for the goal of this research. Nevertheless, the results are consistent with what one would expect given the construction of the data. That is to say that global spatial autocorrelation based on contiguity results in larger, positive spatial autocorrelation for the OGCs than for the other units. This makes sense because contiguous OGCs likely share component governments with each other. Spatial autocorrelation based on distance results in a Moran's I value for the OGCs near zero, indicating almost perfect randomness. While this suggests a lack of a pattern in the spatial distribution of OGC cumulative property tax rates, this would be expected given the radial distribution of cumulative property tax rates across the metropolitan area. In any event, only the contiguity measure of global spatial autocorrelation among OGCs is substantially different from the measure for the other governmental types. This lends only weak support for the research hypothesis.

Though it is difficult to make a rigorous statistical comparison of the LISA measures, this analysis provides some of the most interesting results. While the LISA map for cities does present a pattern of high-high property tax rates and spatial autocorrelation in the urban core, the map for OGCs produces a spatial distribution more clearly consistent with general patterns of metropolitan development.

Figure 12 displays within city variation of the ratio of school performance to cumulative tax rate. This ratio can be thought of as a measure of what tax payers are getting for their money when all taxing jurisdictions are taken into account. The variation of a measure like this may be important from the point of view of municipal government as it includes the kind of information that property owners incorporate into their locational decision making. It is also important to researchers as it aggregates public good data into comparable units. The data in Figure 12 demonstrate the degree to which the cumulative value of public goods varies within cities across a metropolitan area.

\section{Conclusion}

This study demonstrates two things: OGCs constitute distinct units of analysis from their component local governments and OGCs more accurately represent the combinations of local public goods received by citizens and businesses than single government types. These points are demonstrated statistically and graphically in this paper. The general proposition of this paper is that rather than the dichotomy between fragmentation and regionalization found in the literature, the provision of local public goods is best measured as a continuous set of variables that are spatially distributed across a metropolitan area. Thinking of them and measuring them in this way can provide researchers with a finer grained picture of local public good provision.

\section{Conflict of Interests}

The author declares that there is no conflict of interests regarding the publication of this paper.

\section{References}

[1] "Governing: The States and Localities", Number of Local Governments by State, 2013, http://www.governing.com/govdata/number-of-governments-by-state.html.

[2] C. M. Tiebout, "A pure theory of local expenditures," The Journal of Political Economy, vol. 64, no. 5, pp. 416-424, 1956.

[3] E. S. Mills and W. Oates, Eds., Zoning and Land Use Controls, Lexington Books, Lexington, Mass, USA, 1975.

[4] J. S. Zax, "Is there a Leviathan in your neighborhood?" The American Economic Review, vol. 79, no. 3, pp. 560-567, 1989.

[5] R. W. Wassmer, "Property taxation, property base, and property value: an empirical test of the 'New View,' National Tax Journal, vol. 46, no. 2, pp. 135-159, 1993.

[6] E. Plummer, "Evidence on the Incidence of residential property taxes across households," National Tax Journal, no. 4, pp. 739753, 2003.

[7] S. Billings and T. G. Thibodeau, "Intrametropolitan decentralization: is government structure capitalized in residential property values?" Journal of Real Estate Finance and Economics, vol. 42, no. 4, pp. 416-450, 2011.

[8] G. K. Turnbull and S. S. Djoundourian, "Overlapping jurisdictions: substitutes or complements?" Public Choice, vol. 75, no. 3, pp. 231-245, 1993.

[9] C. Berry, "Piling on: multilevel government and the fiscal common-pool," American Journal of Political Science, vol. 52, no. 4, pp. 802-820, 2008.

[10] C. R. Martell, "Debt burdens of overlapping jurisdictions," Municipal Finance Journal, vol. 28, no. 2, pp. 1-23, 2007.

[11] "Minnesota Department of Revenue," "Chapter 06.02-Unique Taxing Areas". Property Tax Administrator's Manual, 2010, http://www.revenue.state.mn.us/local_gov/prop_tax_admin/at_ manual/06_02.pdf. 
[12] B. S. Frey, "Functional, overlapping, competing jurisdictions: redrawing the Geographi borders of administration," European Journal of Law Reform, vol. 5, no. 3-4, pp. 543-555, 2005.

[13] J. M. Ross, J. C. Hall, and W. G. Resh, "Frictions in polycentric administration with noncongruent borders: evidence from Ohio school district class sizes," Journal of Public Administration Research and Theory, vol. 23, no. 1, 2013.

[14] US Census Bureau, Annual Estimates of the Population of Metropolitan and Micropolitan Statistical Areas: April 1, 2010 to July 1, 2012 (CBSA-EST2012-01), 2012, http://www.census .gov/popest/data/metro/totals/2012/index.html.

[15] "Collin Central Appraisal District," Tax Rates and Exemptions, 2012 Tax Year, 2012, http://www.collincad.org/ccad/reports/ rates_exemptions.php.

[16] "Dallas Central Appraisal District," 2012 Ad Valorem Tax Rates For Dallas County, 2012, http://www.dallascad.org/TaxRates .aspx.

[17] “Dallas Central Appraisal District," 2012 Rates and 2012 Exemptions, 2012, http://www.dentoncad.com/index.php?option= com_docman\&task=cat_view\&gid=171\&Itemid=62.

[18] “Ellis Appraisal District," 2012 Rates Per \$100 and 2012 Homestead Exemptions, 2012, http://www.elliscad.org/pdfs/2012_ TAX_RATES.pdf.

[19] “Central Appraisal District of Johnson County," "Rates", 2012, http://www.johnsoncad.com/rates.php.

[20] "Kaufman County Appraisal District," "Kaufman Tax Rates", 2012, http://www.kaufman-cad.org/PDFs/WEB\%202012\% 20TAX\%20RATES.pdf.

[21] "Parker County Appraisal District," “Tax Rates, 2012 Tax Year”, 2012, http://www.isouthwestdata.com/client/webTaxRates.aspx? dbkey $=$ parkercad\&time $=20138241845013$.

[22] "Rockwall Central Appraisal District," "History of Tax Rates", 2012, http://www.rockwallcad.com/pdfs/Historyof TaxRates.pdf.

[23] “Tarrant Appraisal District," “2012 Tax Rates per \$100 Valuation for Tarrant County”, 2012, http://www.tad.org/Webpages/2012_ tax_rates.cfm.

[24] "Wise County Appraisal District," “Tax Rates, 2012 Tax Year", 2012, http://www.isouthwestdata.com/client/webTaxRates.aspx? dbkey $=$ wisecad \&time $=20138241849001$.

[25] "Texas Education Agency," "District Accountability Ratings", 2013, http://ritter.tea.state.tx.us/cgi/sas/broker.

[26] K. J. Meier and L. J. O’Toole Jr., "Public management and organizational performance: the effect of managerial quality," Journal of Policy Analysis and Management, vol. 21, no. 4, pp. 629-643, 2002.

[27] L. Anselin, "Local indicators of spatial association-LISA," Geographical Analysis, vol. 27, no. 2, pp. 93-115, 1995. 

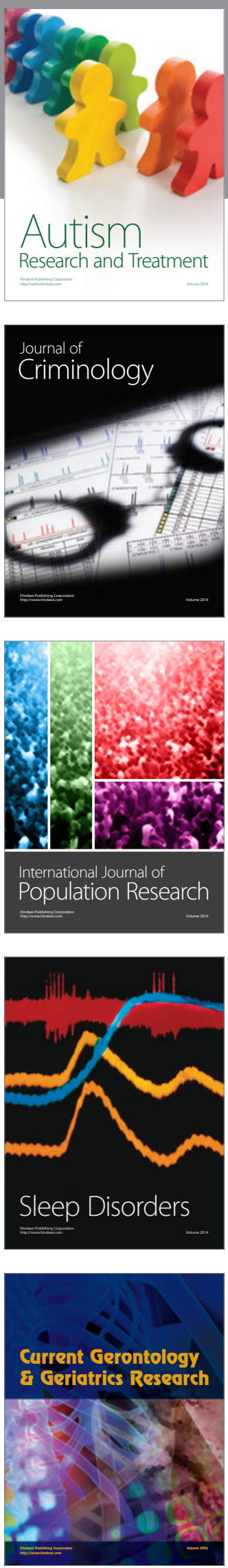
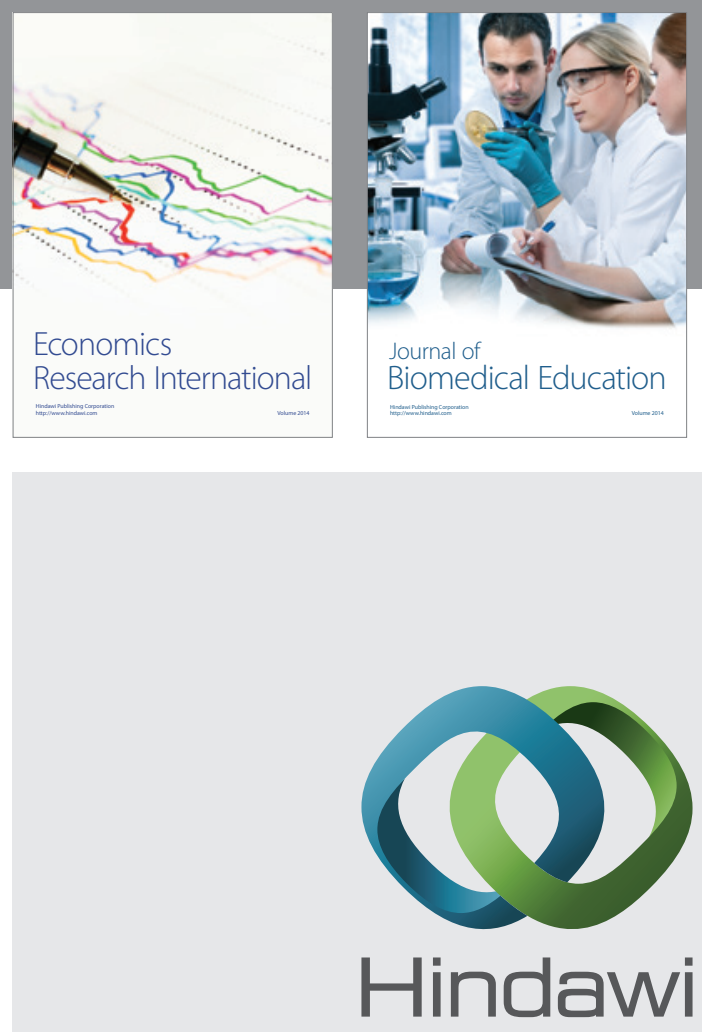

Submit your manuscripts at

http://www.hindawi.com
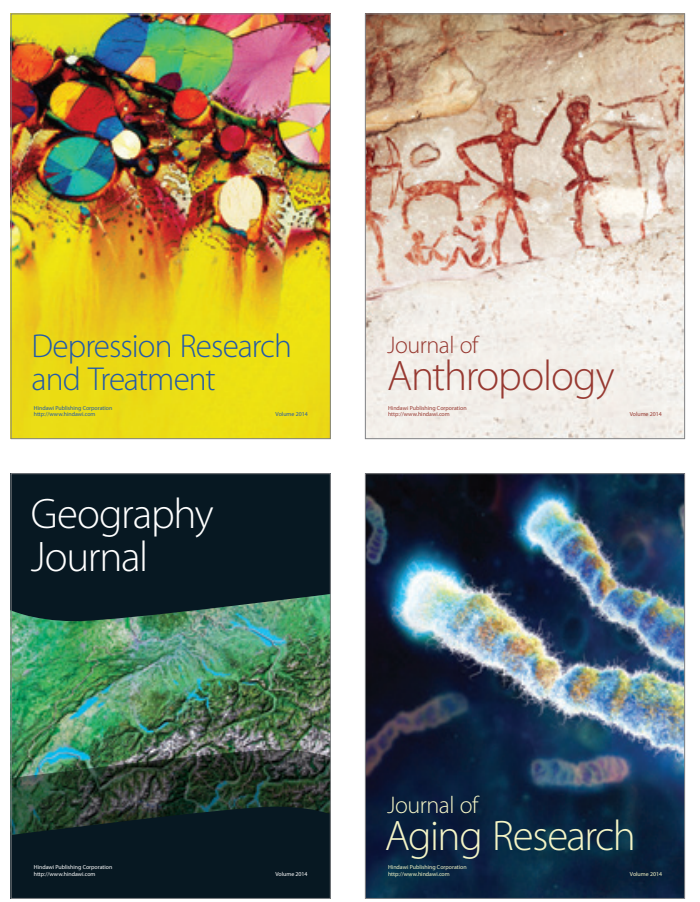
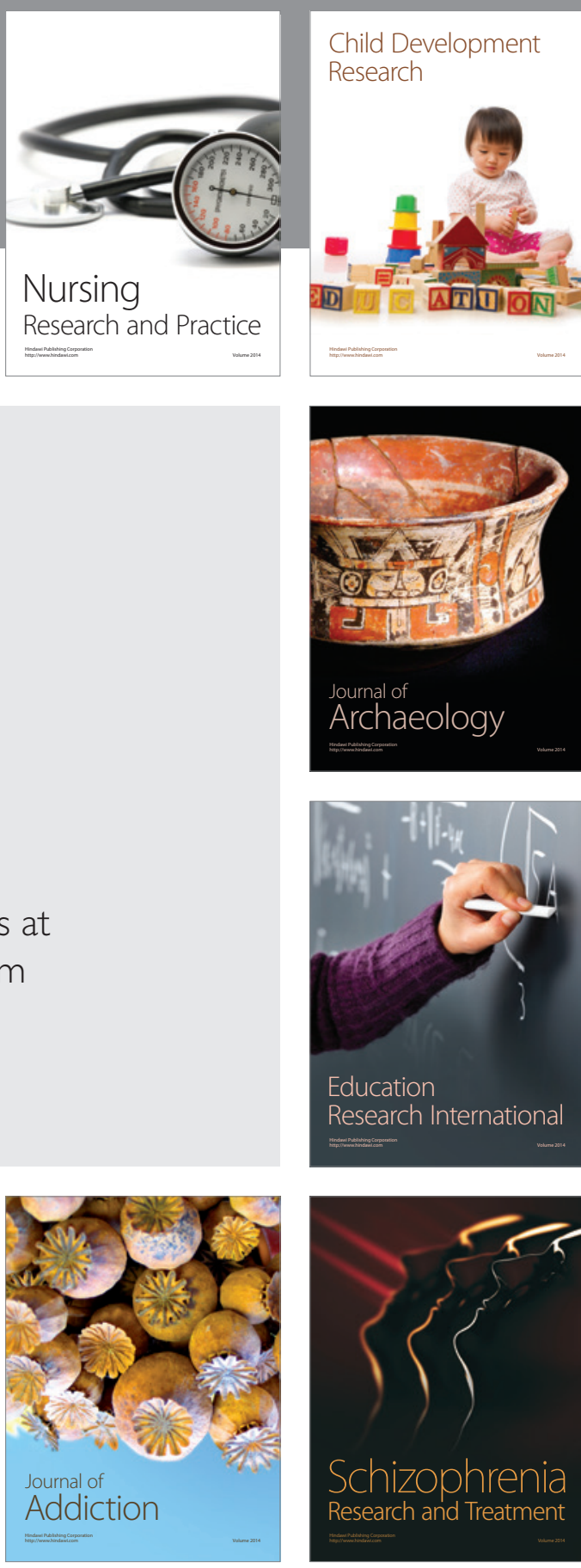

(D)
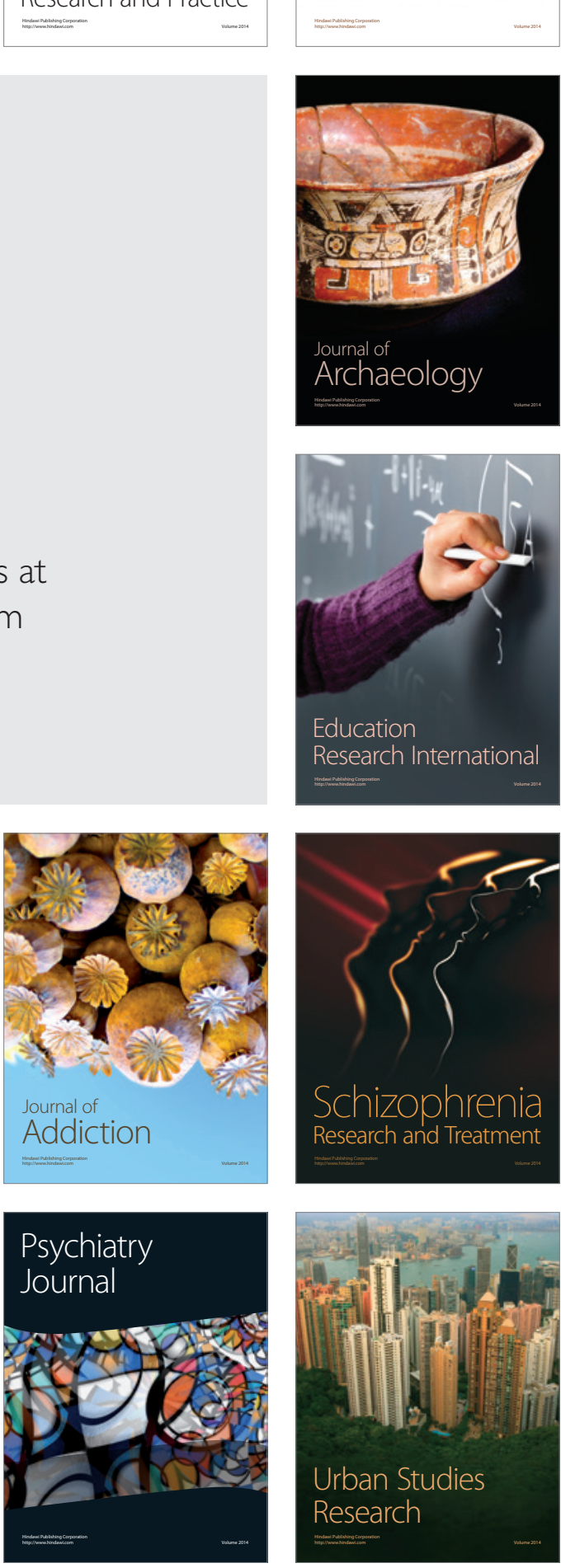